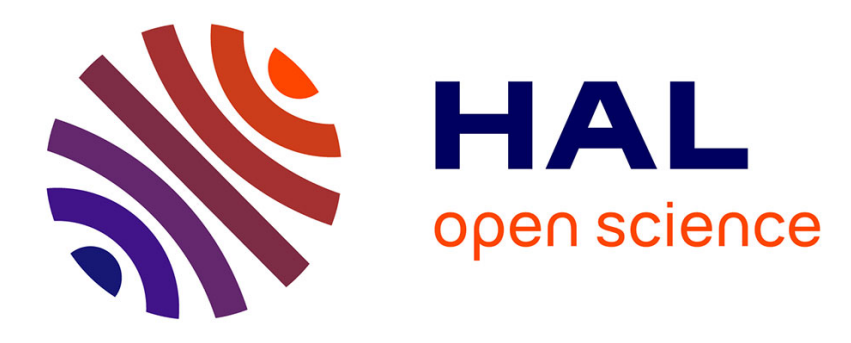

\title{
User-Oriented Requirements Engineering
}

Alistair Sutcliffe

\section{To cite this version:}

Alistair Sutcliffe. User-Oriented Requirements Engineering. 1st and 2nd International Workshop on Usability- and Accessibility-Focused Requirements Engineering (UsARE 2012 / UsARE 2014), Jun 2012, Zurich, Switzerland. pp.11-33, 10.1007/978-3-319-45916-5_2 . hal-01631313

\section{HAL Id: hal-01631313 https://hal.inria.fr/hal-01631313}

Submitted on 9 Nov 2017

HAL is a multi-disciplinary open access archive for the deposit and dissemination of scientific research documents, whether they are published or not. The documents may come from teaching and research institutions in France or abroad, or from public or private research centers.
L'archive ouverte pluridisciplinaire HAL, est destinée au dépôt et à la diffusion de documents scientifiques de niveau recherche, publiés ou non, émanant des établissements d'enseignement et de recherche français ou étrangers, des laboratoires publics ou privés. 


\title{
User-Oriented Requirements Engineering
}

\author{
Alistair Sutcliffe \\ School of Computing and Communications \\ University of Lancaster, UK \\ sutcliag@lancaster.ac.uk
}

\begin{abstract}
A method for analysing emotion and motivation in requirements engineering (RE) is described. The method extends personal RE where requirements are for individual users and their needs. Theories from the psychology of emotion and motivation are introduced and applied in a top-down pathway motivated by system goals to influence users, and a bottom-up scenario-based path to analyse affective situations which might be produced by user-oriented RE. Use of agent technology in storyboards and scenario analysis of affective situations is described and illustrated with case studies in health informatics for persuasive technology applications.
\end{abstract}

Keywords: Personal requirements, emotion, motivation, scenarios, interactive agents, persuasive technology, health informatics.

\section{Introduction}

At first sight people's emotions may seem to have little relevance to requirements engineering (RE), since handling emotion, "a strong feeling deriving from one's circumstances, mood, or relationships with others" (OED), involves general interpersonal skills rather than RE methods per se. Emotions may be manifest in meetings, negotiations, and inter-personal communication aspects of requirements analysis, where sensitivity to emotional responses of stakeholders may give vital clues about the appropriateness and acceptability of goals and requirements [1]. However, emotions may be implicated in a growing class of applications where goals are personal $[2,3]$ since they relate to individual people. For example, achieving personal goals may evoke pleasure, while failing to achieve a personal goal may cause pain and frustration. Considering emotion as part of the requirements picture for personal goals enables designers to anticipate human emotional responses and mitigate their downsides, for example by providing sympathetic advice when goals are not achieved or relaxing goals to avoid disappointment.

Many advisory or explanatory systems have a high-level goal to influence human behaviour; for example, marketing in e-commerce aims to persuade people to buy products, while e-health systems may attempt to influence users towards improving their lifestyle. These applications, frequently described as persuasive technology or captology [4], incorporate design features which play on people's emotions. Somewhat surprisingly, people tend to react to even minimal human presence on computers by treating the computer representation (i.e. virtual agent, character or even a photograph of a person) as if it were a real person. The CASA (Computer As Social Actor) effect [5] is extremely influential, hence choice of 
media, characters, and dialogue content can all be manipulated to evoke emotional responses. User interface technology has now progressed to enable development with character-based agents as a standard technology [6]. Embodied Conversational Agents (ECAs) are equipped with a range of features that can be used for emotive effect: facial expressions, gaze, scripted voice, and body posture. Requirements analysis therefore needs to address how people may react to character-based interfaces, to plan for productive influences of human emotion and to anticipate adverse responses. User-Oriented Requirements Engineering (UORE) may also raise ethical issues; for example, failure to anticipate possible human responses to personal or design goals may cause anger and disappointment that ethical statements and plans should avoid.

Further motivation to consider human emotion within the requirements process arises from the rapid growth of social software. Requirements for software tools to create social applications such as e-communities need to consider social emotions, such as empathy in social relationships, and efficacy (social empowerment) in collective action. Design principles for e-community sites [7] draw attention to social emotions of responsibility and encourage a sense of belonging, while inclusive design for e-communities has to encourage active participation so users do not feel annoyed at being left out or that, while they participate, others are free loaders [8].

As more applications become oriented towards entertainment and personal systems, requirements will become increasingly focused on users as individuals rather than on goals for groups of stakeholders. Personal requirements have been addressed in the context of assistive technology [2] and where individuals' behaviour needs to be monitored, so that attainment of personal goals can be assessed. However, analysis of users' affective reaction to requirements and exploration of designs has received little attention in the RE community apart from some consideration in games $[9,10]$. This paper proposes a model and process for analysing the role of emotion in interactive, user-centred applications, with requirements directed towards agent-based interfaces and social software. It does not address the more general problem of handling emotion during the requirements process since this perspective concerns inter-personal skills and communication rather than RE per se. In the next section, previous literature in RE and related disciplines is reviewed. In section 3, models and theories of motivation and emotion are briefly reviewed, with their relevance to RE. A process of analysing emotional responses by stakeholders and specifying requirements for affective applications in described in section 4, followed by an illustration of the process in case studies of persuasive e-health applications. The paper concludes with a discussion of the prospects for personally oriented RE and affective applications.

\section{Related Research}

The role of emotion in games applications was analysed by Callele et al. $[9,10]$ who described a process of scripting with storyboards and scenarios for planning user interaction. Design effects to evoke emotions such as surprise and fear were annotated on to drawings of the game world; however, no particular model of emotion was proposed. Emotions formed a component of a requirements analysis process which addressed stakeholder values in RE [11]; however, in this case 
emotions were treated from the viewpoint of stakeholder-analyst interaction, with some guidelines for requirements management if emotional responses were detected, e.g. user frustration might indicate disagreement with goals or requirements not representing their views. Furthermore, Thew and Sutcliffe [1] did not consider the role of emotion in personalised applications.

Value-based design [12] elicits user feelings and attitudes to potential systems by presenting cue cards associated with possible emotional responses and user values. Scenarios and storyboarding techniques are used to elicit stakeholder responses, but value-based design does not focus directly on user emotions; instead, it aims to elicit users' attitudes and feelings about products and prototypes as an aid towards refining requirements with human-centred values. Values and affective responses have been investigated by Cockton et al. [13] in worth maps, which attempt to document stakeholders' views about products or prototypes. Worth maps may include emotional responses, but their main focus, similar to value-based design, is to elicit informal descriptions of potential products expressed in stakeholders' language of feelings, values and attitudes. In human-computer interaction, the concept of User Experience (UX) has emerged to describe affective aspects of products [14] and hence what might be regarded as requirements for user acceptance. UX draws attention to aesthetics and enjoyable properties of interactive applications, but no guidelines have been proposed on how to analyse UX or for designing features to deliver an enjoyable user experience.

The role of emotion in user-centred design of products was reviewed by Norman [15], who argued that good design should inspire positive emotional responses from users, such as joy, surprise and pleasure; however, Norman was less forthcoming on how to realise affect-inducing design, beyond reference to the concept of affordances, intuitively understandable user interface features. Techniques for exploring affect in requirements include use of personas, pen portraits of typical users, including their feelings and possibly emotion in their personalities [16]. Personas were developed further into extreme characters [17] as a means of eliciting stakeholders' feelings in response to provocative statements about designs, although neither of these techniques considers the role of emotion explicitly. Requirements for emotion are tacitly included in design of embodied conversational agents $[18,19,20,21]$ as scripts for controlling facial expression, posture and gaze of virtual agents. Scripts control expression of emotions by the agent, and may be embedded in an overall plan for conversation with users to influence their mood and emotional responses. However, the ECA literature contains no techniques for eliciting or specifying desired emotional responses.

\section{Theories of Emotion and Motivation}

The starting point for the analysis is a focus on personal goals, i.e. goals related to an individual's needs. Two areas of psychology are relevant to personal needs: first, motivation theory, which explains deep-seated goals or drives which determine our behaviour; and secondly, emotions, which characterise our automatic reactions to events and situations. The intention is to augment personal goal analysis with knowledge from psychology about goals which are tacit (motivation] and reactions that may arise when goals or motivations are frustrated (emotions). We might 
anticipate rational reactions when obstacles [22] confront goals; however, not all reactions are rational, hence knowledge of human emotion might be usefully deployed in the RE process. Motivations and emotions will also play a role in amplifying understanding of RE models which include relationships between (human) agents such as trust, responsibility [19], and agent properties including capabilities, skills and preferences [23].

Psychologists distinguish between emotions, which are specific responses, and moods, which reflect more general good or bad feelings. Moods are temporary, whereas emotions are part of our cognitive response and persist as memories of responses to events, objects and people. Emotions may be either positive (pleasure and joy) or negative (fear, disgust) and may have a force, e.g. worry or anxiety is a mild form of fear. There are many theories of emotion; however, three have received more attention in the design of software systems. First, Norman's [15] model divides emotional responses into three layers: the visceral layer which produces psychosomatic responses to fear and anger; a behavioural layer that dictates actions in response to emotion, such as rejecting a product; and finally a reflective layer in which emotional responses are rationalised, e.g. disappointment in a product after a poor user experience. Norman advises that software design should encourage emotions of pleasure, joy and surprise for positive behavioural and reflective responses, but gives little advice on how to achieve such responses in a design. Second, ECA designers have favoured Ekman's [24] theory which characterises a simple set of basic emotions: anger, disgust, fear, sadness and surprise, which are communicated by facial expressions. The third more comprehensive theory is the OCC model [25] which contains a taxonomy of 22 emotions, classified into reactions to events, agents (other people) and objects which may be either positive or negative. A simplified view of the OCC taxonomy is shown in Fig. 1. Reaction to events depends on whether the consequences concern oneself (+ve hope, -ve fear) or others, and then the impact of the event (satisfaction, fears confirmed, relief, disappointment). Responses to objects may either be mild (like or dislike) or stronger (love/hate). Emotional response to agents' actions depends on who the action relates to (self, others, group) and then the perceived effect of the action and whether it was positive, such as pride as a positive response to one's own action, or reproach as a negative reaction to another person's action. Event-related emotions are responses to situations and changes in the environment and are related either to oneself or others in terms of consequences and impact. For example, joy is a positive assessment of an event (e.g. birthday party) relating to oneself with a general impact, and hope is the positive emotion in a specific response to getting a present, which may happen (satisfaction) or not (disappointment). Some emotions such as gratification, remorse, gratitude and anger are complex responses to events and agents/objects. Even though the OCC model is comprehensive it does not account for social emotions such as empathy (+ve reaction to an agent) and belonging (+ve reaction to group membership) [26]. In spite of these limitations, the OCC model is suitable for application to requirements analysis since the event/agent/object taxonomy and decision tree can be applied to analysing emotional reactions. Individual stakeholders may experience emotions in response to events, objects or agents produced by the software system, or which may be a consequence of events and objects in the system environment. Once a range of "emotion inducing" states have been identified, 
responses to them can be planned as requirements for software agents and their behaviour.

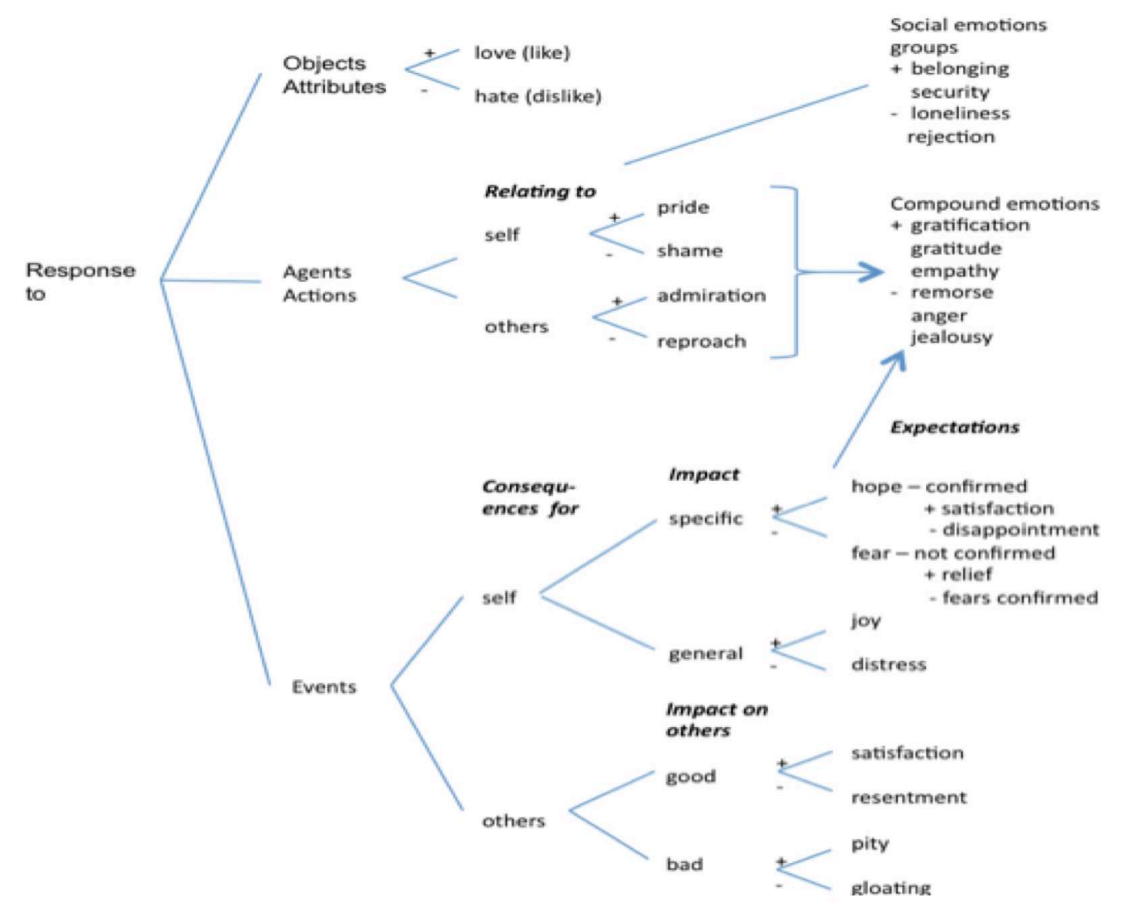

Fig. 1. OCC model decision tree for classifying emotions; augmented with social emotions

\subsection{Motivation Analysis}

Motivations are related to personality, and can be considered as long-lasting, highlevel personal goals [2]. Motivations were classified by Maslow [27] into levels ranging from basic bodily needs such as hunger and thirst, to higher-level needs for security, comfort and safety, and finally socially related motivations of self-esteem and altruism. Table 1 summarises the more important motivations for requirements analysis, synthesised from Maslow's motivation theory [27] and other theories of human needs (e.g. [26]). Motivations are not easy to detect [28] so elicitation guidance from the description in column 2 can only provide hints to guide questions, some of which are suggested by the motivation type itself, i.e. questions about interest in learning, or willingness to help others. Column 3 suggests implications for personal goals and needs for each motivation type; for example, self-efficacy, curiosity and learning point towards the need for opportunities to experiment which may suggest requirements for customisable or programmable systems.

Table 1. Motivations and their consequences 


\begin{tabular}{|c|c|c|}
\hline Motivation & Description & Implications \\
\hline Safety & $\begin{array}{l}\text { Self preservation, avoid injury, } \\
\text { discomfort }\end{array}$ & $\begin{array}{l}\text { Avoid danger: safety critical applications; avoid } \\
\text { natural and artificial threats to self }\end{array}$ \\
\hline Power & $\begin{array}{l}\text { Need to control others, authority, } \\
\text { command }\end{array}$ & Work organisation, responsibility, control hierarchy \\
\hline Possession & Desire for material goods, wealth & $\begin{array}{l}\text { Resource control, monetary incentives, ownership, } \\
\text { products, wealth }\end{array}$ \\
\hline Achievement & $\begin{array}{l}\text { Need to design, construct, } \\
\text { organise }\end{array}$ & $\begin{array}{l}\text { Project \& personal goals, completing tasks, lifestyle } \\
\text { targets }\end{array}$ \\
\hline Self-esteem & Need to feel satisfied with oneself & $\begin{array}{l}\text { Linked personal goals, personal achievement, also } \\
\text { perception of self }\end{array}$ \\
\hline Peer-esteem & Need to feel valued by others & $\begin{array}{l}\text { Inclusion in groups, teams social feedback and } \\
\text { rewards, praise }\end{array}$ \\
\hline Self-efficacy & Confidence in own capabilities & $\begin{array}{l}\text { Confidence building, training, encourage } \\
\text { responsibility }\end{array}$ \\
\hline $\begin{array}{l}\text { Curiosity, } \\
\text { learning }\end{array}$ & $\begin{array}{l}\text { Desire to discover, understand } \\
\text { world }\end{array}$ & $\begin{array}{l}\text { Opportunities to experiment, time to explore, self } \\
\text { tutoring and learning support }\end{array}$ \\
\hline Sociability & Desire to be part of a group & $\begin{array}{l}\text { Group membership and social relationships, } \\
\text { collaboration in work }\end{array}$ \\
\hline Altruism & Desire to help others & Opportunities and rewards for helping, selfless act \\
\hline
\end{tabular}

Safety subsumes basic motivations to satisfy hunger, thirst, and protect oneself. Power, possession and achievement are all related directly to personal goals, although in different ways. Power is manifest in actions and social relationships, and is associated with responsibility, trust and authority. Possession is more personal, concerning goals to own resources, wealth or products. Achievement (or failure) is the end state of most goals, although in motivation theory it spans many personal goals as a lifetime ambition. Self- and peer-esteem concern personal perceptions of self and of self by others, which may indirectly be related to goals if achievement is frustrated, leading to a decline in self-esteem. Motivations of self- and peer-esteem can indicate designing systems to suit individual needs; for instance, in e-commerce, marketing tools can be customised to praise customers [4] and thereby improve their self-esteem (positive wellbeing). An example of fostering peer-esteem is giving thanks and praise for contributions within e-communities [7] and broadcasting such praise to the whole user community.

Self-efficacy is realising one's potential, hence increasing abilities and responsibility. Altruism and sociability are social motivations driving group behaviour, the need to belong to groups and undertake selfless acts, which incidentally increase peer esteem and hence the sense of belonging to the group. People with high sociability motivation will collaborate and cooperate with others in group working. Motivations can be measured by questionnaires; however, in most RE simple question checklists of motivations are sufficient to direct requirements investigation.

\section{Applying Emotions and Motivations to RE}

Emotions and motivations are used as tools for thought in scenario-based RE for personal RE. Motivational analysis complements goal-based requirements approaches; in contrast, emotions are reactions, and consequently these fit with 
scenario-based RE [29] as a means of assessing the implications of situations. The UORE process is summarised in Fig. 2.

The process follows two related pathways: first, the analysis path starts from users' needs where the motivation component in the UORE method is applied; then, affective situations are considered by identifying scenarios for the user roles and stakeholders who may experience significant emotions, followed by analysis of the situations and events that may lead to emotional experiences. Obstacle analysis contributes by investigating barriers to achieving personal goals, motivations or in problems in achieving the desired emotional reaction. The second planning path has its origins in design goals or high-level system requirements to influence users and their personal goals. System agents and actions are specified in response to anticipated situations. The two pathways interact: the system goals planning pathway suggests situations for follow-up analysis, while affective situations identified in the domain may alter plans and system goals. Analysis of affect may be stimulated by the type of application; for example, games and entertainment applications aim to manipulate user emotions, while e-commerce applications have design goals to influence decisions of individual stakeholders and user groups.

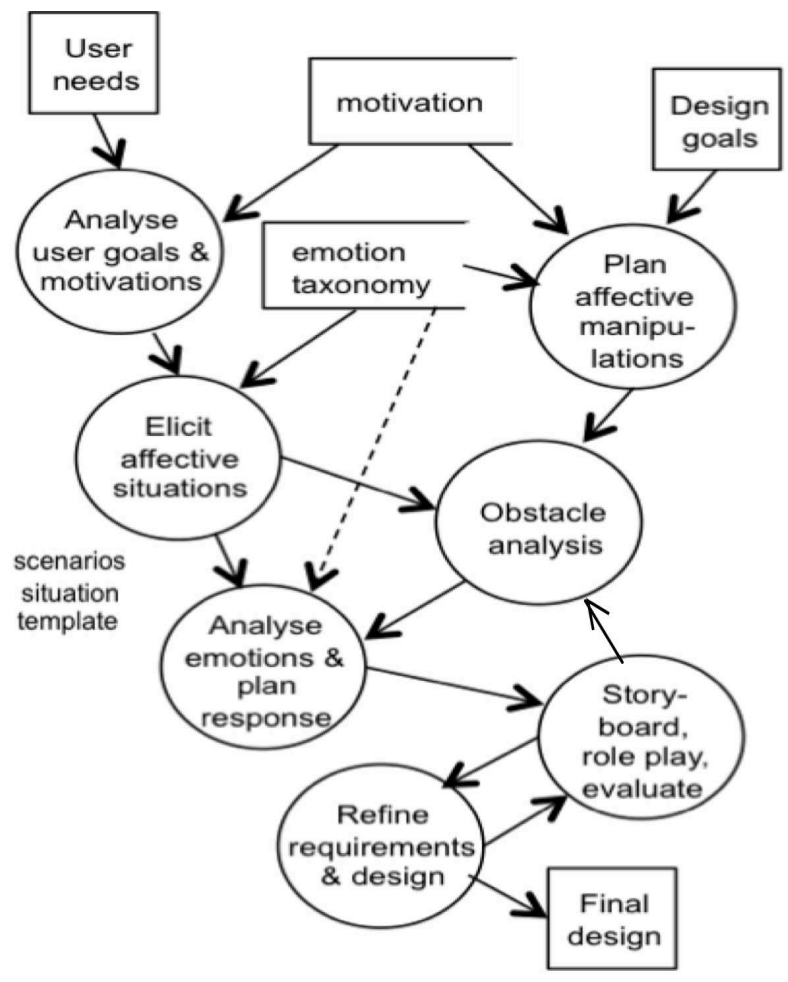

Fig. 2. Summary of the User-Oriented Requirements Engineering (UORE) process

Design goals may arise from the need to motivate users to change their behaviour or persuade them towards certain decisions in applications such as 
healthcare (lifestyle behaviour), marketing e-commerce (purchasing decisions) or social e-communities (persuading people to participate).

\subsection{Analysing User Goals and Motivation}

Analysis of personal goals will follow conventional interviews and scenario-based techniques augmented with motivation analysis using the taxonomy. At this stage user motivations are identified as an extension of personal goals. For example, personal goals to improve one's diet and take exercise will be related not only to achievement but also to self esteem (feeling good about oneself) and peer esteem (improving standing among friends for having lost weight). Barriers to personal goals will often have motivational implications such as frustrated achievement, power and possession, which in turn may have knock-on effects on self-esteem and peer-esteem. Knowledge of user motivations is also applied to planning system responses to affective situations. Since emotional responses are frequently related to motivations as well as to our short-term goals and aspirations, analysis of motivations, goals and emotions is inevitably intertwined. A summary of motivations and possible obstacles to their realisation, and emotional responses to frustrated motivation, is given in Table 2 .

Table 2. Motivations, obstacles and responses

\begin{tabular}{|c|c|c|}
\hline Motivation & Obstacles & Potential emotion (possible response) \\
\hline Safety & $\begin{array}{l}\text { Dangerous events, malevolent } \\
\text { agents }\end{array}$ & $\begin{array}{l}\text { Fear, hate (remove cause or relocate user, add } \\
\text { defences and counter measures to events }\end{array}$ \\
\hline Power & $\begin{array}{l}\text { Change to authority, } \\
\text { responsibility }\end{array}$ & $\begin{array}{l}\text { Anger, shame, resentment (compensation, change } \\
\text { people, relationships) }\end{array}$ \\
\hline Possession & $\begin{array}{l}\text { Reduced resource control, } \\
\text { monetary incentives }\end{array}$ & $\begin{array}{l}\text { Anger, jealousy, resentment (reallocate resources, } \\
\text { responsibilities, change people) }\end{array}$ \\
\hline Achievement & Constraints on goals, actions & $\begin{array}{l}\text { Anxiety, frustration resentment (change goals, remove } \\
\text { constraints) }\end{array}$ \\
\hline Self-esteem & $\begin{array}{l}\text { Adverse events, goals not } \\
\text { achieved }\end{array}$ & $\begin{array}{l}\text { Shame, anger (re-focus goals, emphasise other } \\
\text { achievements) }\end{array}$ \\
\hline Peer-esteem & Adverse interactions, events & Rejection, loneliness (focus on +ve social relationships) \\
\hline Self-efficacy & $\begin{array}{l}\text { Limitations on actions and } \\
\text { responsibilities }\end{array}$ & $\begin{array}{l}\text { Disappointment, distress (improve opportunities, } \\
\text { challenges) }\end{array}$ \\
\hline $\begin{array}{l}\text { Curiosity, } \\
\text { learning }\end{array}$ & $\begin{array}{l}\text { Excessive workload, time, } \\
\text { resources }\end{array}$ & $\begin{array}{l}\text { Disappointment, reproach (provide time, change } \\
\text { workload) }\end{array}$ \\
\hline Sociability & $\begin{array}{l}\text { Group conflict, personality and } \\
\text { authority clashes }\end{array}$ & $\begin{array}{l}\text { Rejection, resentment, loneliness (negotiate problems, } \\
\text { change group membership, responsibilities) }\end{array}$ \\
\hline Altruism & Limitations on actions & $\begin{array}{l}\text { Distress, disappointment (provide opportunities, } \\
\text { rewards) }\end{array}$ \\
\hline
\end{tabular}

This is used in obstacle analysis to consider the interaction between motivation, emotions and personal goals. The motivations and emotions in Table 2 can be used to prompt questions in both directions. Emotional reactions to a scenario may indicate motivational problems, while obstacles to personal goals and related motivations indicate emotional consequences which will need to be addressed either in the social system or design of information content and artificial agents. 


\subsection{Identifying Affective Situations}

The first step is to identify the range of potential affective situations, then to trace the source responsible for emotional reactions in the system content or environment. Situation analysis is directed towards identifying the possible emotional response and its source, then establishing requirements for system agents and responses using the template illustrated in Table 3.

Table 3. Affective situation requirements template, with notes

\begin{tabular}{ll}
\hline Application & Situation ID \\
\hline $\begin{array}{l}\text { Agents and actions } \\
\text { Objects }\end{array}$ & $\begin{array}{l}\text { People in the scenario, possible actions and communication } \\
\text { Objects and design artefacts } \\
\text { Events (previous) }\end{array}$ \\
$\begin{array}{l}\text { Expected events in the environment, with their source, when known. User } \\
\text { memory of previous events } \\
\text { System response }\end{array}$ & $\begin{array}{l}\text { As identified from the above and obstacle analysis } \\
\text { Remove cause, mitigate effect }\end{array}$ \\
Agent requirements & Agents' actions for mitigation \\
Other requirements & Non-agent responses, avoid cause, etc. \\
\hline
\end{tabular}

Identifying agents and stakeholder groups is standard practice in RE analysis and modelling [31,32,33,34]. Scenarios, use cases and storyboards, all commonly practised RE techniques, can be adapted for "affective situation" analysis with stakeholder groups and individual users. Scenarios describing potential emotion invoking incidents may be elicited from stakeholders or created by requirements analysts to explore user reactions to personal goals and design features. Storyboards and sketches are used to illustrate scenarios and presented to users to capture their responses. Since agent-based technology is now cheap and easy to use, lightweight prototypes can be developed to explore design options with a range of emotional expressions by agents [6]. Some examples of facial expression of emotions using agent prototyping tools are illustrated in Fig. 3.

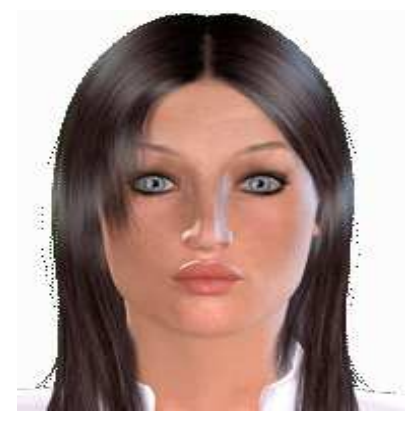

"You seem to have problems; can I help you ?.....

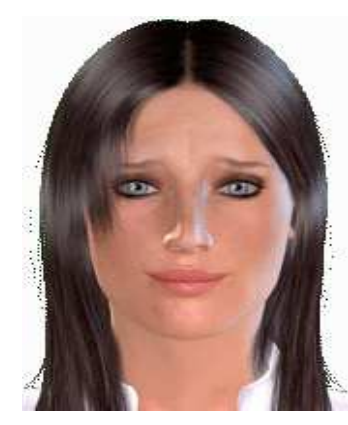

All is ok please continue"

Fig. 3. Expression of emotion by agent's face with dialogue excerpts 
Facial expression alone is somewhat ambiguous, as might be discerned from Fig. 3 , so it needs to be combined with dialogue, for example, "You seem to be having difficulty in placing this order; please select the product again" and "Thank you for your order; please proceed to payment" in a typical e-commerce sequence. Emotional expression is even more effective when prosody (voice tone) is used, and text to speech output with limited tonal expression is provided by agent development tools.

\subsection{Analysing Situations and Emotions}

Tracing the source of emotions follows the template and OCC decision tree to elicit the reasons for the response, then identifying the source in the system environment, content or the design itself. The OCC decision tree helps to identify potential emotions and their causes by asking questions about the source of the problem (agents' actions, objects' attributes, events), who it affects (self, other stakeholders), and the consequences and impact of the problem, as well as any previous related experiences (expectations). Affective reactions may be caused either by the system design, the content of the design, agents, especially people and other stakeholders, actions, or events in the system environment the user has to deal with. Poor implementation of requirements or missing requirements may evoke frustration and anger in more extreme cases. User reaction to the content of applications and websites may be more complex as the response may be caused by information and messages conveyed by text or speech, images of people or natural phenomena, or even sounds and music. Situations involving the system environment range from other people in computer-mediated communication and social software, to events in the world or user goals that the system has to respond to by advising, persuading or directing the user to take action.

Anger tends to be associated more closely with agents and people, so the presentation of characters, opinion and values that clash with the stakeholder's viewpoint should be investigated. Fear is related to events as well as to specific agents, so events in the system environment or described in the system content (e.g. website information) should be questioned. Disgust is a strong, visceral emotion usually associated with content, for example images of putrefying food. Socially oriented emotions have roots in reactions to people and events, so in this case the stakeholder's relationship with others may need to be investigated, through the history of events involving the user and others in the system environment. Social emotions are also important considerations in social computing applications, with privacy and security implications. For example disclosure of secrets may cause shame (in own behaviour), jealousy (in others), remorse (in injudicious actions which have offended others) and so on. Scenarios of information disclosure and privacy controls can explore the types and strengths of emotional responses.

\subsection{Obstacle Analysis}

Planning system responses to user emotions can be helped by analysing obstacles to motivations and personal goals. If responses can invoke appropriate user motivations then potential negative emotions might be deflected or converted into positive responses (e.g. convert dislike into like by changing an object or design). 
Obstacles to personal goals follow the established practice of inquiry into what assumptions, resources, and events may prevent a goal being achieved [22]. This is extended to investigate users' motivations. Since motivations are long-term goals, obstacles are more general and possibly more persistent than may be expected for short-term personal goals. Table 4 gives some guidance in analysing possible reasons for affective reactions for a sub-set of OCC negative emotions. This contributes to obstacle analysis since the causes (agents, people, events, etc.) may hinder the achievement of personal goals with limited guidance on countermeasures for the obstacles. Barriers to power, possession and achievement may be found in social technical systems as modelling in $i^{*}$ strategic dependency diagrams, where changes are made to responsibility relationships, power and authority, or access to resources by agents. Motivation obstacles indicate possible adverse consequences for human stakeholders. Motivational consequences may be mitigated by design in the social system, for example, poor self-esteem arising from a lack of achievement may be alleviated by improving training, changing the organisation of work, or re-setting targets to make them more achievable

Table 4. Emotions, possible causes and responses

\begin{tabular}{|c|c|c|}
\hline Emotion & Obstacles, causes & Possible responses \\
\hline Hate & $\begin{array}{l}\text { Actions of people or things, value } \\
\text { clashes }\end{array}$ & $\begin{array}{l}\text { Remove object, agent; change focus to self- } \\
\text { achievement }\end{array}$ \\
\hline Anger & $\begin{array}{l}\text { Offensive events, people, things, } \\
\text { values }\end{array}$ & Remove cause, mitigate reasons \\
\hline Fear & $\begin{array}{l}\text { Threats to self, dangerous objects, } \\
\text { situations }\end{array}$ & Remove threat or user from situation, add protection \\
\hline Disgust & Offensive objects, people & Remove cause, change location \\
\hline Jealousy & People's actions, objects & Mitigate reasons, change focus to self \\
\hline Shame & Own actions self-image & Analyse reasons, change focus to achievement \\
\hline
\end{tabular}

Emotional responses indicated from motivation obstacle analysis suggest further scenarios for situation analysis where the implications can be explored by roleplaying situations in which the generic obstacles are made more realistic and concrete, e.g. being turned down for promotion is an obstacle to achievement and has a negative impact on self-esteem.

\subsection{Planning Responses}

The source of the emotional response is traced back to the agent action or event, and response scenarios are planned to mitigate the anticipated negative emotion. Once the source is known, requirements to deal with the situation can be specified. There are three main routes: first to remove the source; secondly to reassure the users and diffuse the emotion by reducing the significance or impact of the reaction; and finally planning a system response to change negative affect into its related positive emotion, e.g. fear is converted into relief by explaining that the event's consequences are not what the user expected. Removing the source in content can be achieved by editing to remove the offending image, text or event; however, changing sources in the system environment may not be an option, so a mitigation strategy may be 
necessary. For example, if resentment is felt in response to the success of others, then a better outcome might be to convert this into satisfaction or deflect the negative emotion by urging the user to reflect on their own achievements. Resentment might be reduced by counselling the user to ignore the event as unimportant or reflecting on one's own success rather than envying others.

Hate and its milder manifestation, dislike, may be encountered as a response to missing requirements, poor user interface design, or when users are frustrated by poor design. With content, the causes may arise from a clash between the user's beliefs and values and information or opinions expressed in the content. Adverse reaction to personalities is another likely cause. Emotional responses to products and designed artefacts are usually easier to deal with since these can be traced back to the feature causing dislike. Disliked features indicate poor design or missing/inappropriate requirements.

Positive emotions are less of a concern in situation analysis since there are fewer implications for system requirements, although when goals for influencing user behaviour are present, then scenarios need to be developed that describe the desired positive emotion, e.g. pleasurable experience for persuading users. To illustrate, in an e-commerce application selling high-quality design goods such as jewellery, the high-level goal is to influence the user to buy the product. The user is a member of the public, objects are the jewellery products, and the intended emotions are curiosity, pleasure and desire. Requirements for a sales agent virtual character are to empathise with the user, using a smiling facial expression to communicate interest and pleasure in explaining the product, followed by actions to demonstrate product qualities, and use of gesture and gaze to draw attention to these features. In games applications there will a sequence of affective situations, in which the user-player is led through situations with agents and events to evoke fear, anxiety, surprise and relief as the game sequence unfolds. Action scripts and sketches of the game's virtual world amplify the requirements described in the template.

\section{Illustrative Case Studies}

In this section, implementation of the User-Oriented RE process in two persuasive technology applications in e-health is described. Both applications are at the feasibility exploration stage, so only initial pilot studies have been conducted; however, they do illustrate application of the UORE method and provide preliminary experience.

\subsection{Detecting Early Onset of Cognitive Impairment}

The system is intended to help early diagnosis of cognitive dementia and Alzheimer's disease among the elderly. Unfortunately, Alzheimer's disease is diagnosed too late in too many people, by which time there is little that medical science can do to help; however, if the disease is detected early, then treatment can delay its onset and ameliorate its symptoms. Early onset can be detected by memory tests, patterns of word use and motor reaction times, so the high-level system goal is to remotely and unobtrusively monitor people's use of home computers and text-based messaging via e-mail and social networking sites. There are many complex requirements involving 
data and text mining to produce early onset diagnostic indicators, which do not concern this paper; instead, analysis of the users' possible reactions to the system is described, with requirements to persuade elderly users to self-refer for follow-up tests and appropriate medical treatment.

The users' motivation is safety, to avoid Alzheimer's disease if possible, with personal goals to participate as volunteers in the trial for altruistic reasons. Affective situations in this case are an obvious consequence of the design goal to warn the user. The affective requirements problem is to analyse people's potential reaction to system diagnoses. The diagnostic part of the system will not be perfect, hence there is uncertainty about the results and the danger of false positive diagnoses, which could provoke fear about the consequences. Scenarios based on these assumptions were explored. If the system detected signs of dementia then this information could be distressing to the user. This raises questions about how the information should be communicated to the user, and the appropriate system response to different diagnostic signs. Using the OCC model, the source of anticipated emotions of fear and distress are the event (message), which has consequences for self (the user) with a specific impact when the feared expectation (diagnosis of dementia) is confirmed. Relief or fear confirmed are also possible depending on the results of follow-up tests. This may also have a general impact leading to distress and fear of the future. This is summarised in the template shown in Table 5.

The next step is to specify the system response. In this case the mirror emotion (relief) can be explored since the diagnosis is uncertain, so suggestions for follow-up tests can be specified to confirm or negate the initial diagnosis with reassuring messages that many initial signs turn out to be false alarms.

Table 5. Situation template: cognitive impairment diagnosis

Situation: Diagnosis of problems, low confidence

\begin{tabular}{ll}
\hline Agents and actions & User, possibly their kin \\
Objects & Text, graphs feedback presentation \\
Events (previous) & Message warning about possible cognitive impairment (patient history) \\
Expected emotions & Anxiety, fear, distress, relief \\
System response & Mitigate consequences, reassure user, empathise \\
Agent requirements & Agent sympathises with user, communicates \\
Other requirements & Supplementary information, communication with doctors, kin and friends. \\
\hline
\end{tabular}

Consulting medical experts with explanations of tests in memory clinics is another system response. The social emotion of empathy is a further means of dealing with distress, hence requirements for social support might be explored, for instance the acceptability of letting close friends know via a social network. A range of scenarios (see Fig. 4) were developed to explore different means of communicating the potentially distressing message, with system responses ranging from no emotion (just the facts), to expression of empathy by agent characters.

Other design requirements involve choice of media to deliver the message (text, voice, agent character plus voice/text), as well as the content and format of the message (polite, sympathetic tone). 
Scenario: You are presented with evidence of memory problems from the computer monitor. How would you feel about the messages presented, and the follow-up advice to complete more self-assessment tests?
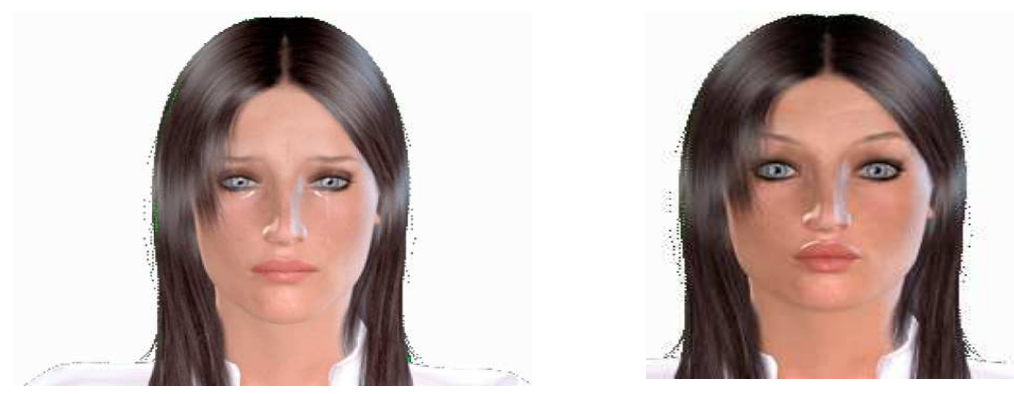

Agent: "Sorry to disturb you, but I have found a few signs of problems with your memory. These might not be significant but I think it would be helpful to try a few follow-up tests: see the following link."

Fig. 4. Scenario and agent storyboard for the weak diagnostic signs situation

These scenarios, personal goals and motivations were investigated with obstacle analysis to identify possible barriers to system goals (to encourage self-referral for follow-up tests), for example self-denial that the user has a medical problem. Requirements indicated from preliminary analysis of the storyboard scenarios showed individual differences in affective responses. Some users preferred simple factual communications, whereas others liked the empathetic agent. Older characters were suggested to match the user audience, also using a doctor to evoke more trust. Content requirements included simple explanations of the reasons for diagnosis, with limited disclosure of the information to close friends or kin in the user's social network. All users felt that, apart from letting their very best friend know if the follow-up tests did confirm the problem, any disclosure would cause them distress and unnecessary fear among friends.

\subsection{Persuasion for Exercise Conformance}

The second application focuses on system initiative to persuade the user to take exercise as part of a recovery programme after hospital treatment for a fall. Analysis follows the planning pathway to persuade the user to carry out a set of exercises. The personal goals are to recover from the fall and achieve mobility. Obstacles may be insufficient motivation or physical difficulty in carrying out the exercises. Requirements are for an agent character-based interface to persuade the user (an elderly patient) to take exercise on a regular basis. The situation template for motivating exercise is shown in Table 6. 
Table 6. Situation template: exercise motivation

Situation: Exercise conformance feedback

\begin{tabular}{ll}
\hline Agents and actions & User, exercise movements, procedures \\
Objects & Exercise videos, graphs feedback presentation \\
Events (previous) & Feedback messages on performance \\
Expected emotions & Satisfaction, anxiety, fear, distress, relief \\
System response & Encourage user to complete routine \\
Agent requirements & Congratulate good conformance, mild displeasure for poor conformance \\
Other requirements & $\begin{array}{l}\text { Progress displays, advice possible group motivation- group progress and } \\
\text { communication }\end{array}$ \\
\hline
\end{tabular}

The personal goals and motivations are:

- Improve health (top level)

- Perform exercises as best as I can

- Make progress each day

- Achievement, self-esteem, peer-esteem.

The design problem is motivating the user to take exercise, which involves communicating a sense of achievement with the corresponding emotions of satisfaction and pride in their achievement, while also motivating their self-esteem, and in a group context peer-esteem. The agent role is a trainer-tutor to encourage exercise conforming to a set regime. To motivate the patient, the agent needs to empathise with the user's situation, be encouraging, and communicate pleasure when the user achieves their exercise goals. The potential for positive and negative responses by the agent needs to be explored, so if the patient does not take the recommended exercise then disappointment and mild reproach may be necessary, followed by more positive encouragement. The social dimension in this application is setting up a self-help group of users to motivate each other by sharing experience and progress feedback. Privacy concerns may lead to resentment (when others do better). A range of scenarios are created, varying the agent's response from mild to stronger emotions to explore which combinations are more acceptable and effective.

\section{Case Study and Lessons Learned}

UORE was applied in the SAMS project (Software Architecture for Mental-health Self-management) which is investigating the potential of computer monitoring of user interaction and e-mail for inferring change in cognitive function to diagnose early signs of dementia and mental health problems. The efficacy and acceptability of the SAMS approach depend critically on discovery of affect-laden user requirements, since diagnosis of dementia is a potentially stressful situation. The obstacles to understanding the emotion-laden requirements involve new imagined systems where few contemporary analogues exist, and a challenging mix of ethical and emotional factors.

UORE was applied in a requirements discovery process with five workshops that were conducted with a total of 24 participants (14 male, 10 female, age range 60-75, median 66), with a median four participants/session plus two facilitators and one to 
two moderators from the Alzheimer's Society (AS) or the Dementias and Neurodegenerative Diseases Research Network (DeNDRoN). The method was used to construct scenarios to illustrate design variations to mitigate the fear of diagnosis, as well as addressing emotions of despair, anger and frustration which may be felt if there was insufficient explanation for the computer-based diagnosis. The scenarios also explore anxiety that may be caused by invasion of privacy in computer-based monitoring and data security concerns.

The design mock-up illustrated in Fig. 5 shows the simple text message version of the interface, using reassurance to try and ameliorate possible fear, as well as a polite tone to reassure the user.

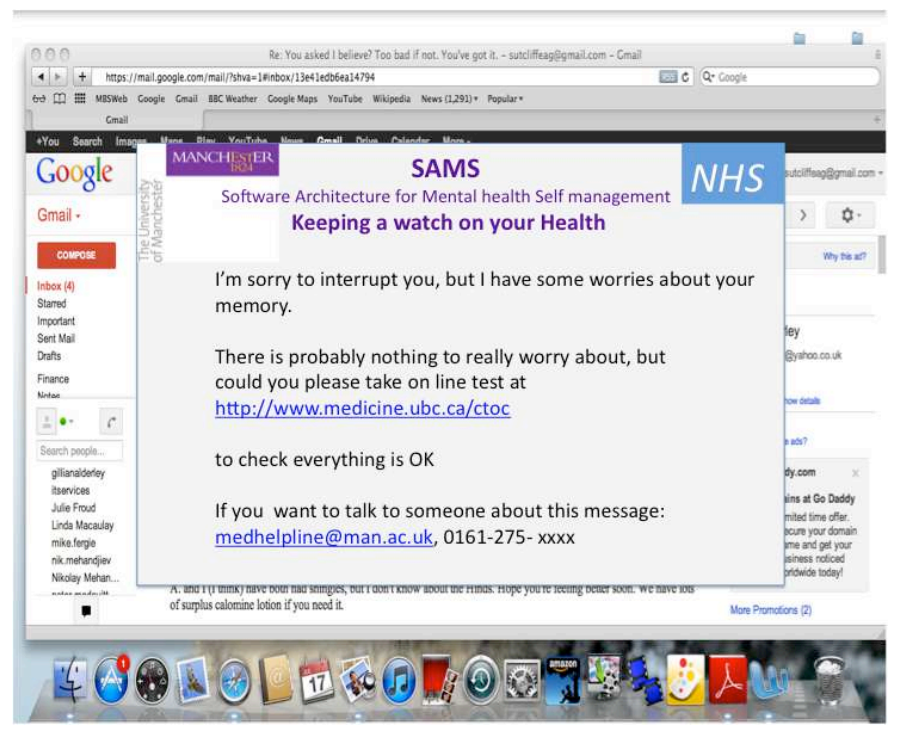

Fig. 5. Storyboard for diagnostic message situation: text version

The ECA version of the feedback interface with additional information to explain the diagnosis is illustrated in Fig. 6. Eight mock-ups were created to explore different design treatments: modality of information delivery (simple text/avatar/video), +/- additional explanation, and tone of the message more/less empathetic. The users were presented with a scenario similar to the one illustrated in Fig. 4, with the variation of imaging the news from a self and other (friend/relative) viewpoint. The scenario mock-ups were presented in sequence either in group workshops or in individual interviews.

All workshops were structured in two sessions lasting approximately 1 hour. In the first session the SAMS system's aims, major components and operation were explained, followed by presentation of eight PowerPoint storyboards illustrating design options for the alert-feedback user interface, such as choice of media (video, text, computer avatars), content (level of detail, social network) and monitoring (periodic feedback, alert only, explicit tests). The second session focused on discussion of privacy issues in monitoring computer use, data sharing and security, 
ethical considerations, emotional impact of alert messages, users' motivations and likelihood of taking follow-up tests.

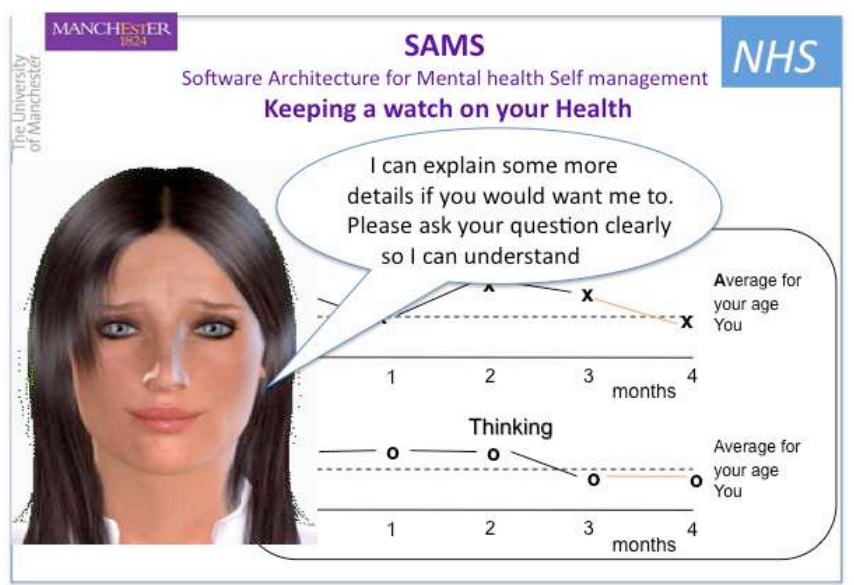

Fig. 6. Storyboard for diagnostic message with added explanation: avatar version

\subsection{Workshop Results}

All participants reported they would feel anxiety and distress over a possible warning message, although the strength of emotional reaction varied, with some people feeling the motivations outweighed the potential distress. Opinion was never unanimous on any design option. There was no consensus on choice of media (text/video/avatar), although a majority in all workshops favoured provision of more detail and availability of regular reports (content). Use of video was favoured in four workshops where participants suggested that self-help (how to cope) and explanatory videos (dementia mitigation treatments) were important motivators for persuading them to take follow-up action. Active monitoring (e.g. quizzes) was favoured by all, but (e.g. card) games were rejected in three of the five workshops. Participants in all workshops suggested that configuration controls for different design options would be welcome.

All participants expressed anxiety over privacy and security arising from monitoring their computer use. Although they were reluctantly willing to share their data with the researchers for analysis, most participants insisted they should have control over their own data. Sharing data with their close kin/friends had to be under their control and the majority would not share information or the alert with their doctor. The majority in all workshops were willing to allow monitoring of their computer use and e-mail text content, suitably anonymised to protect the identities of other parties to conversations. Most participants expected to experience anxiety and fear if they received an alert message, although they all stated that they would take a follow-up test. Contact with a human expert or carer was cited as an important form of support, with connections to support groups (e.g. the Alzheimer's Society) as additional sources of information to motivate people to take follow-up tests. 


\subsection{Interview Results}

Requirements issues raised in the workshops were explored further in 13 interviews following a similar structured approach of explaining the SAMS system, presenting scenarios to illustrate similar design options with discussion on privacy, security and ethical issues. Questions in the interviews also probed users' reactions to different levels of monitoring (e.g. actions, text) and their perceived trade-off between benefits/motivations versus fears/barriers for adopting the system and taking followup action after an alert message. Respondents (4 male, 9 female), ranging from 67 to 89 years old (median 72 ), were all interviewed in their own homes, apart from three sessions carried out in a community centre.

Anxiety, distress and fear (in a few individuals) were the main emotional reactions. The interviews produced less consensus than the workshops for the user interface design requirements. Most respondents (11/13) favoured the plain text alert message over other media options. Active monitoring by a 'cognitive quiz' and a weekly diary was favoured by the majority (11/13) although card games were less popular (8).

The respondents were even more concerned about privacy and security, possibly because three participants had recently experienced phishing attacks on the Internet. However, only two individuals were unwilling to have their e-mail content monitored. Opinions on minimal data sharing and the need to maintain control over their own data were similar to the workshop participants'. The majority of the respondents (11/13) expressed anxiety about being monitored, and they expected to experience discomfort, fear and worry when they received an alert message, although all these 11 participants stated they would take the follow-up test: "better to know the bad news" was a common statement. However, ten respondents reported that they could not realistically imagine how they would react in a real-life situation. Five individuals noted that further explanation after the alert message would be vital and all reported that their main motivation for using the system was efficacy: a feeling of being in control by self-management of their health.

\subsection{Summary and Lessons Learned}

Several issues which were categorised as values (see [33]) and emotional requirements [24] were discovered to have an important bearing on the requirements and design options:

Trust: in the SAMS system, the universities (system authors), healthcare professionals, follow-up test websites and authors thereof.

Motivations: efficacy, desire for self-control, altruism (participation might help research on dementia).

Emotion: anxiety, distress and fear of negative alert messages, uncertainty over personal reaction.

The UORE method identified the major user goals and non-functional requirements from analysis of emotional reaction to the scenarios and mock-up prototypes. However, the range of values, motivations and emotions which were discovered was modest, even though the analyst was expert in such analysis and actively sought these insights. Fear and anxiety were the main emotions and a sub-group of users emerged 
who showed stronger emotional reactions, suggesting that these users may be less willing adopters of SAMS. The analysis also discovered another sub-group of users who showed less emotional reaction, which is unusual given the very real prospect of dementia affecting the lives of our senior citizen interviewees. We have two interpretations of this result. Either people find it difficult to imagine how they would respond in reality given a fictitious scenario, or these people may be unwilling to express their emotional response while feeling their motivations (wellbeing, being in control) outweigh the downsides of potentially distressing news.

The UORE method is still being refined, as early experience with storyboard and preliminary requirements analysis leads to improvements in the method. The research has followed an action research approach in which the first version of the method was applied in practice, leading to insight into problems and improvements to the method. The nature and quantity of the advice incorporated in the method is an open question, as analysis proceeds by a team of medical and requirements-human factors researchers. One problem with affect-oriented research is that people are rarely completely candid about expressing emotion [34]. Some users expressed the concern that they only felt emotion in real life and that imagining how they would feel in response to scenarios was not easy. Another problem was negative reaction to the agents; one user preferred to communicate with real people rather than computer images in affective situations. However, motivations and discussion of feelings were productive when assessing responses to different agent designs. The analysis side of the method, eliciting emotional situations which might occur, appears to be more difficult than the synthesis-design side where reaction to specific agent designs is being assessed. Tools for developing prototype agents have proved successful in demonstrating a range of facial expressions and scripted interactions, so exploration of affective requirements for agent designs does seem to be a promising approach.

\section{Discussion}

Presentation of situations to explore human motivations, emotions and attitudes is a novel contribution to RE. UORE extends previous concepts of personal requirements [2] as well as addressing requirements for advanced UI technology where agent/character-based interfaces are becoming more common. Motivation and emotion analysis are particularly pertinent to social computing applications where computer-mediated interactions need to be considered. The UORE method is not intended to supplant conventional RE; instead, it is a way of augmenting scenariobased RE with person-oriented and social considerations. Even though the method is in its early stages of development, UORE does show some promise in producing insight into personal problems in applications where individual experience and goals are paramount. It also addresses requirements analysis for the new generation of user interfaces where character/agent-based interaction is becoming widespread, and in applications where system goals aim to influence users [4]. The method fits within $\mathrm{RE}$ practices of goal-based and scenario-based RE, amplifying them, especially in personally oriented applications. The method may also be applied to content analysis in websites and requirements for customisable systems where users can choose their own goals and preferences. 
While emotions and motivation are psychological constructs which require indepth knowledge for analysis of human problems, the UORE method delivers a digestible sub-set of psychology, which could be used by non-experts. Experience to date has involved medical personnel who are conversant with the psychology of emotion from their training, so testing the method with non-experts is part of the future research agenda. To deliver the method's advice more effectively we will create a hypertext website so users can explore the links between motivation, emotions, obstacles and possible mitigations. The scenario and storyboard analysis has demonstrated that affective issues can be explored with users who are not experts.

RE methods for modelling motivation and emotional influences on requirements goals have been proposed [35,36] following an agent-role, soft-goal modelling approach. However the People Oriented Software Engineering method [35] did not adopt any specific model of emotion beyond Norman's framework of three levels of emotional reaction [15], so their role modelling approach does not provide any specific guidance for analysing the impact of users' emotions on requirements. UORE, in contrast, does provide specific advice based on a sound theory [25]. Emotional requirements could augment modelling of social influences in $i^{*}[31]$, and UORE could be applied to the goals, skills preferences approach [23] and RE modelling of socio-technical systems. Considering emotions and motivation may help in modelling agents and their relationships, since trust and responsibility are already part of the $i *$ family of models $[31,32]$. Knowledge of individual agents may help inspection-based analysis, while emotional analysis can help problem identification in scenario-based investigations. Analysis of emotions may also be applied to requirements monitoring of progress relating to personal goals. Current sensory technology enables body posture and facial expression to be automatically analysed to detect emotional responses such as disappointment when personal goals are not achieved, or dislike of products. The OCC model has been formalised [37] so there is the prospect of creating emotional analysis tools for agent-based specifications. UORE could also extend games-based specification methods $[9,10]$ and requirements for interactive virtual environments such as SecondLife. In conclusion, UORE has extended a theme in RE which started with a focus on personal goals $[2,3]$ and the user as a subject of requirements analysis. It also extends earlier work on emotion in RE [38] which analysed the socio-technical implication of affective reactions to inappropriate features, tacit knowledge and managerial changes. Finally, UORE raises questions about how RE deals with new generations of systems where goals are not just functional but relate to human feelings and values.

\section{Acknowledgements}

This research was partially funded by EPSRC Grant EP/K015796/1 Software Architecture for Mental-health Self-management (SAMS). 


\section{References}

1. Thew, S., Sutcliffe, A.G.: Investigating the Role of Soft Issues in the RE Process. In: Proceedings, 16th IEEE International Requirements Engineering Conference, pp. 63-66. IEEE Computer Society Press, Los Alamitos CA (2008)

2. Sutcliffe, A.G., Fickas, S., Sohlberg, M.M.: PC-RE: A Method for Personal and Contextual Requirements Engineering With Some Experience. Requirements Engineering, 11, 157-163 (2006)

3. Fickas, S., Robinson, W., Sohlberg, M.M.: The Role of Deferred Requirements in a Longitudinal Study of Emailing. In: Proceedings RE-2005, pp. 145-154. IEEE Computer Society Press, Los Alamitos CA (2005)

4. Fogg, B.J.: Persuasive Technology: Using Computers to Change What We Think and Do. Morgan Kaufmann, San Francisco (2003)

5. Reeves, B., Nass, C.: The Media Equation: How People Treat Computers, Television and New Media Like Real People and places. CLSI/Cambridge University Press, Stanford CA/Cambridge (1996)

6. Artificial Intelligence Foundation, http://alice.pandorabots.com/

7. Preece, J., Maloney-Krichmar, D.: Online Communities. In: Jacko, J., Sears, A. (eds.) Handbook of Human-Computer Interaction, pp. 596-620. Lawrence Erlbaum Associates, Mahwah NJ, (2003)

8. Kraut, R.E.: Applying Social Psychological Theory to the Problem of Group Work. In Carroll, J.M. (ed.) HCI Models, Theories, and Frameworks: Toward a Multidisciplinary Science, pp. 325-356. Morgan Kaufmann, San Francisco (2003)

9. Callele, D., Neufeld, E., Schneider, K.: Balancing Security Requirements and Emotional Requirements in Video Games. In: Proceedings, RE 2008, pp. 319320. IEEE Computer Society Press, Los Alamitos CA (2008)

10. Callele, D., Neufeld, E., Schneider, K.: Augmenting Emotional Requirements with Emotion Markers and Emotion Prototypes. In: Proceedings, RE 2009, pp. 373-374. IEEE Computer Society Press, Los Alamitos CA (2009)

11. Thew, S., Sutcliffe, A.G., DeBruijn, O., McNaught, J., Procter, R., Venters, C., Buchan, I.: Experience in E-science Requirements Engineering. In: Proceedings, 16th IEEE International Requirements Engineering Conference, pp. 277-282. IEEE Computer Society Press, Los Alamitos CA (2008)

12. Friedman, B.: Value Sensitive Design. In: Schular, D. (ed.) Liberating Voices: A Pattern Language for Communication Revolution, pp. 366-368. MIT Press, Cambridge MA (2008)

13. Cockton, G., Kujala, S., Nurkka, P., Hölttä, T.: Supporting Worth Mapping with Sentence Completion. (LNCS, vol. 5727). Springer, Berlin (2009)

14. Hassenzahl, M., Schöbel, M., Trautmann, T.: How Motivational Orientation Influences the Evaluation and Choice of Hedonic and Pragmatic Interactive Products: The Role of Regulatory Focus. Interacting with Computers, 20, 473479 (2008)

15. Norman, D.A.: Emotional Design: Why We Love (or Hate) Everyday Things. Basic Books, New York (2004)

16. Cooper, A., Reimann, R., Cronin, D.: About Face 3: The Essentials of Interaction Design. Wiley, Indianapolis (2007) 
17. Djajadiningrat, J.P., Gaver, W.W., Fres, J.W.: Interaction Relabelling and Extreme Characters: Methods for Exploring Aesthetic Interactions. In: Conference Proceedings, Designing Interactive Systems: Processes, Practices Methods and Techniques, pp. 66-71. ACM Press, New York (2000)

18. Picard, R.W.: Affective Computing. MIT Press, Cambridge MA (1997)

19. Bickmore, T., Cassell, J.: Social dialogue with embodied conversational agents. In: Van Kuppevelt, J., Dybkjaer, L., Bernsen, N. (eds.) Natural, Intelligent and Effective Interaction with Multimodal Dialogue: Proceedings of the International Joint Conference on Artificial Intelligence. Kluwer Academic, New York (2004)

20. Cassell, J.: Embodied Conversational Interface Agents. Communications of the ACM, 43, 70-80 (2000)

21. Pelachaud, C., Carofiglio, V., De Carolis, B., De Rosis, F.: Embodied Virtual Agent in Information Delivering Application. In: Proceedings, First International Joint Conference on Autonomous Agents and Multi-Agent Systems, Bologna (2002)

22. Van Lamsweerde, A., Letier, E.: Handling Obstacles in Goal-oriented Requirements Engineering. IEEE Transactions on Software Engineering, 26, 978-1005 (2000)

23. Hui, B., Laiskos, S., Mylopoulos, J.: Requirements Analysis for Customisable Software: A Goals Skills Preferences Framework In: Proceedings IEEE Joint International Conference on Requirements Engineering, pp. 117-126. IEEE Computer Society Press, Los Alamitos CA (2003)

24. Ekman, P.: Basic Emotions. In Dalgleish, T., Power, M. (eds.) Handbook of Cognition and Emotion. Wiley, Chichester (1999)

25. Ortony, A., Clore, G.L., Collins, A.: The Cognitive Structure of Emotions. Cambridge University Press, Cambridge (1988)

26. Bandura, A.: Social Cognitive Theory of Mass Communication. Lawrence Erlbaum Associates, Mahwah NJ (2001)

27. Maslow, A.H., Frager, R., McReynolds, C., Cox, R., Fadiman, J.: Motivation and Personality. Addison Wesley-Longman, New York (1987)

28. Sandelands, L.E., Boudens, C.J.: Feeling at work. In: Fineman, S. (ed). Emotion in Organizations. Sage Publications, London (2000)

29. Potts, C.: ScenIC: A Strategy for Inquiry-driven Requirements Determination. In: Proceedings, 4th IEEE International Symposium on Requirements Engineering, pp. 58-65. IEEE Computer Society Press, Los Alamitos CA (1999)

30. Sutcliffe, A.G.: Analysing the Effectiveness of Human Activity Systems With i*. In: Yu, E., Georgini, P., Maiden, N., Mylopoulos, J. (eds.) Social Modelling for Requirements Engineering, pp. 1139-1195. MIT Press, Cambridge MA (2010)

31. Yu, E.: Social Modelling and i*. In: Borgida, T., Chaudhri, V., Georgini, P., Yu, E. (eds.) Conceptual Modeling: Foundations and Applications: Essays in Honor of John Mylopoulos. LNCS vol. 5600, pp. 99-121. Springer, Berlin (2009)

32. Yu, E.: Introduction to Social Modelling in RE. In: Yu, E., Georgini, P., Maiden, N., Mylopoulos, J. (eds.). Social Modelling for Requirements Engineering, ch. 1. MIT Press, Cambridge MA (2010)

33. Sommerville, I., Kotonya, G.: Requirements Engineering: Processes and Techniques. Wiley, Chichester (1998) 
34. Fineman, S.: Understanding Emotion at Work. Sage Publications, Thousand Oaks CA (2004)

35. Miller, T., Pedell, S., Lopez-Lorca, A.A., Mendoza, A., Sterling, L., Keirnan, A.: Emotion-led Modelling for People-oriented Requirements Engineering: The Case Study of Emergency Systems. Journal of Systems \& Software, 105, 54-71 (2015)

36. Miller, T., Pedell, S., Sterling, L., Vetere, F., Howard, S.: Understanding Socially Oriented Roles and Goals Through Motivational Modelling. Journal of Systems and Software, 85, 2160-2170 (2012)

37. Adam, C., Herzig, A., Longin, D.: A Logical Formalization of the OCC Theory of Emotions. Synthese, 168, 201-248 (2009)

38. Ramos, I., Berry, D.M.: Is Emotion Relevant to Requirements Engineering? Requirements Engineering, 10, 238-242 (2005) 